\title{
A Novel Approach to Assessing Family History in the Prevention of Coronary Heart Disease
}

\author{
Tomohiro Saito', Seilchiro Nanni2, Ikuo Saito², Shiro Nagano², and Sadanobu Kagamimori
}

\begin{abstract}
Family history semes as the most important risk factor in prevention of coronary heart dlsease from youth. Prevalent methods of assessing family history, however, have serious drawbacks : a sudden rise of risk when a farnily member develops the disease; insufficiant control for age among famlly members. We propose a simple quantitative mothod overcoming such drawbacks. Data on family hlstory were obtained by questionnaires sent to 2,393 male high schood students and their cholesterol levels were measured. Famlly risk from each family member was calculated by $\left(30\right.$ / Risk age ${ }^{4}$, where the risk age was age at onset expressed by decade; if absent, it was replaced by preaent age or age at death. A mean scoro in a famlly served as the famlly risk. A total of 1,584 students and 17,127 famlly members were analyzed. The proposed method yielded a statistically significant association (Odds ratio=1.60; 95\% confichence interval: 1.152.25) between the fumily risk (above or below the median) and the student's atherogenic index (abowe or below the soth percentile) calculated from cholesterols. This association was stronger than those by conventional methods. The proposed method may be useful in preventlon acthities and its officioncy needs to be confirmed in other studies.
\end{abstract}

$\checkmark$ Epidemiol, $1997 ; 7: 85-92$.

ago factors, coronary disease, family, human genetics, risk factors

Prevention of adult cardiovascular diseases from childhood and youth has been atracting more attention recently, and a WHO expert committee recommended action wo be caken ". In parallel with health education identifying high risk children occupines a lange part of these activities. Family history, some claimed, is the most importank known risk factur at present ${ }^{25}$, and the nationwide strategy in selective screening of children in the U. S. A. employs farnily history as the risk factor of the first choice *. Thus, a proper evaluation of family history scems to be crucial. However, prevalent methods are inadequate, and no standard method for evaluating family history was proposed by the WHO commintee.

In the litarane there have been two widely used methods +7 and one complex method". The most frequently used and fantitiar is a "qualitative" method in which the number of family members who have developed a disease in question is teken as a natk score ". Another is a "semi-quantitative" method in which the number of family members who developed the disease before a certain age, 55,65 or 50 , is taken as a risk score $64 \pi$. In the other, complex method a family scone is calculated based on the difference between the observed number of affected family members and the expected number cakculated from agespecific cumulative incidence in the general population ?. These methods, however, contain several serious drawbacks in the prevention programs in childsood and youth.

The qualitative method has four serious drawbacks. Fist, no measure is taken to control for age of family members. The risk is assessed as exulal when a family member developed the disease at age 40 or at 60 . It is also assessed equally as no risk when a family member is 40 years of age or 60 without the disease. This is inappopriate; incidence, prevalence or cumulative incidence of coronary heart disease increases nearly expo-

Recelved September 24, 1996 ; accepted December 2, 1996.

'Division of Emviorumental Epidemiology, Nationed Children's Medical Research Center. Tolyo, Japen.

"Health Center, Keio University, Tokyo, Japan.

"Department of Community Medicine, Toyama Medical and Pharmaceutical University, Toyama, Japan.

Adcress for correspondence, proofs and reprint requests : Or. Tomohiro, Saito Enviromental Epidemiology, National Children's

Mecical Pleseanch Center, 3-35-31 Taishido, Setagoya-ku Tokyo, 154 Japan. 
nentially with age ": an age increase of 5 years would lead to a 1.37 times increase in the presence of a positive history of coronary heart disease in a family member . In addition, in diseases under multifactorial inheritance a younger age at onset should be heavily weighted, and a reduced risk should be given to the absence of the disease al old age: this notion was confirmed for cardiovascular diseases

The second trawback is discontinuity of risk. When a family member develops the disease, the risk is incrased suddenly at this point. In a method where young age at anset is more heavily weighted, the risk jumps up. This causes serious problems in the prevention program, since a child at low risk becomes a high risk child suddenty.

The third drawback is inequality in the number of family members. This may result from premature deaths by other disease or from unequal nurnbers of uncles and aumes in families. There is a higher chance of positive history in a family of larger size. Some measumes ned to be taken to account for this factor.

The fourth drawback is the young age of parents for the diseases in question. Most parents of children and youth at target are in their 40 s, wo young to assess familial loads sufficienty from the presence or absence of the past history. This drawback provided arguments on the screening strategies based on family history ${ }^{\mathbf{n}}$ as reconmended by the Nalional Cholesterol Exucation Program in the U. S. A.

The "semi-quantitative" method compensates for the first drawback to some extent; age at onset is dichotomized at the threshobd, but age at onset in the range below the threshold or above the threshodd is not controlled at all. Also the method is not free from the third and fourth drawbacks. The second drawbeck appears at the age of threshold for risk:

The complex method compensates for the first, third and fourth drawbacks well, but it is not free from the second drawback: a sudilen rise of risk. It atso bears a practical disadvantage: age-specific incidence in the general population is required. Probably because of this requirement and the cornplexity of the calculations, it has rarely been used.

We propose here a new simple quantitative method which compensates for the four drawtacks.

\section{MATERIALS AND METHODS}

\section{Sources of Data}

Questionnaines asking for the fanily history of adult atherosclerotic diseases were distributed to all the 2nd-year high school stardents, aged 16 or 17, at a male high school in Japan as part of the sctool health program. The totsl number of sur dents in three study years was 2,393. The questionnaire, filled in at home by parents, collected data on parents, grandparents and uncles and auns ; the tata incleded ; present age or age at death, and age at onset. by decade, of angina pectoris and myocerctial infarction which had been diagnosed $\alpha$ treated by physicians. A recall bias was avoided by collecting the questionnaire before the students' routine health examinations.

In the students' routine health examination at school the total cholestenol was measured by the enzyme method ${ }^{10}$, and the high density lipoprotein cholesterol (HDL cholesterol) by the dextran sulfate $\mathrm{Mg}$ ion precipitation method . All the measurements were carried out at the Sumitomo Bioscience Laboratories (Sagamihara, Kanagewa-ken ). Precision and accuracy of the messurement were checked routinely. The atherogenic index was obtained by ((Total cholesterol - HDL cholesterol) / HDL cholesterol], This index has been most widely used in Japan as a risk indicator for conorary heart disease 18 including among children 14.6 . The high atherogenic index students were defined bere as those above the 90th percentile.

\section{Calculation of Risk Score}

The quantitative evaluation of the family history of coronary beart disease was done in the following way. The procecture is summarized in Table 1. For each fanily menber, a term (30) Risk age)" was calculated. The "Risk age" was ate at onet, by decaste, of coronary heart disease, that is angina pectoris or myoczandial infantion, If the family member had noc developed the disease, present age or age at death served as the "Risk age". Age at onset was obtained by decade age for easy actuisition of such data. This also yields an advantage of giving some weight to a fanily mernber with an onset of the disease: the created difference between present age and onset age rounded to decade strves as the weight in the formula. When the risk age was below 30 , it was replaced by 30 . This was to avoid giving a high score to a family where an uncle or an anu died at a very young age. The figure 30 was employed since we are concerned with the diseases after this age. In the formula the "Risk age" is placed in the denominalor and 30 is plaped

Table 1. Calculation of the tamily risk score.

1.Calculate a score for an individual member by (30Risk age)4. Risk age is either age al oneet by deceite, present age, or age al death.

2.Adjust the uncle-iunt score to a 2-uncle-augt farnily at a patemal and maternal side.

(1) No uncle-aunt farmily: replace with the twice of a parent's score.

(2) One uncle-aunt family: add a parent's score.

(3) More thun two uncle-aunt family: the sum was divided by the number and multiplied by 2.

3. Calculate a family scone.

(1) Double the partents' score.

(2) Sum up grandparents' scores, 2-uncle-aunt scores and doubled parents' scores.

(3) Divide the sum by 12 . 
in the numerator so that the celculated rist varies firom neer 0 , the lowest risk when the risk age is around 100, to 1, the highest risk when the risk age is 30 . In this connection it is noved that the formula gives more weight to younger age. This is appropriate in assessing familial loads under multifactorial inheritance in which a heavily loeded person develops the disease eartier. This is also appropriate for diseases whose agespecific prevalence topers off $\mathrm{at}$ very old age. In addition, it is advantagenus to give more weight to younger age in prevent tion activities from childhood and youth. The 4th power of ( 30 / Risk age) was comployed to make the power closest to that of age-specific proportion of a positive history of coronary beent disease. The power 4 was obeained from the study data in the following way. If a proportion of a positive history of coronary heart disease, $p$, is expressed as $p=a$ (Age $)^{n}$, where $a$ is a constant, then $\log (\mathrm{p})=\mathrm{n} \log ($ Age $)+\alpha$, where $\alpha$ is a constant. The parameter $\mathbf{n}$ was estimated from this formula by giving the ago-specific proportion of a positive history by decade age, chesined from the study dats to the left side and mid-years of the decade age, for example 45 for the $40 \mathrm{ks}$, to the right side. The estimsiod n \pm standend error was $4.0 \pm 0.4$. The closest integer 4 was taken. This procecture would be justified as the regression line of the $\log (\mathrm{p})$ against the $\log (A g$ ) $)$ was very straight from age $30 \mathrm{~s}$ to 60 , followed by a convex curve afterwards. This can be feen from the age-specific proportion of a positive histay of comonary heart disease ploted against an age scale ". The estimated n was faity stable when the estimstion was done for the sepernite 3 study years : $4.1 \pm 0.5,3.5 \pm 0.4$. and $3.4 \pm 0.7$.

Adjustment by the narnber of uncles and aunts was made for the putenal and the mavemal sike separanely. When no uncle or aunt existed, twice the parent's calculated risk score was supplied. When the number of uncle or aunt was one, the father's or the mother's cakculated risk was supplemented. When the mumher was more than 2, the surn of the calculated scores was divided by the number and multiplied by 2 . In all the cases the resultant nist score became the equivalent of a 2uncle-sumt fanily on each side. The number 2 was taken for two reasons. First, 2-uncle-aunt families were the highest in frequency. Second, the number was made equal, on each side, to that of grandparents whose genctic correlation to the student is equal to that of uncles or aunts. This adjustment was done to avoid giving lower scores to a family with less than two uncles/amts.

A family risk for each student was caloulated by incorporating the risk scores of all family members. After dopling the father's and the mother's risk socres, the parents', grandparents', and number-adjusted uncles'-aunts' risk scores were summed up followed by the division by 12 . The parental risk scores were doubled to reflect their twofold genetic correlation to the student as confored with that of other members th. Division by $12-n$ ot by 10 , the mumber of family members-was done to make the family risk between near 0 and $I$, responding to the doubling of parental scores. The farnily risk was calculated for angina pectoris and myocantial infarction separately and their mean served as the family risk score of coronary heart disease.

It is noted here that the aljustment to the equal number of uncles and aunts was done to avoid giving lower scones to families with less then two unck-aunt fanilies. This is illustrated in the following simple example. Suppose a 2-uncle-aunt family in each paredal side with the following risk age : parents : 40,40 ; grandparents: $70,70,70,70$; uncles or aunts: 40,50 , 40,50 . The family risk score became 0.1910 . The family risk score for a similar family with one uncle or amt with age 50 in each parental side becomes 0.1660 , when the sum is divided by 10 . The lower score results from a fewer number of young members, that is uncks or aunts, conplened to the full 2-uncleaum family. Even if a mean is taken for a family score, it becomes lower reflecting a fewer number of young members.

In addition to the proposed method described above, the two alternative methods mentioned in the introduction were employed as comparisons, One was the "qualitative" method where 2 points were given when a parent developed a coronary heart disease and 1 point was given when other members developed the disease. The summed points served as the family risk. Urually no adjustmem is made for missing members who died of other causes, and uncles and aunts ane not included ". The other method is the "semi-quantitative" method 4,4"n. One point was given for the onset of angina pectoris or myocardial infarction below age 60 in a family, inclusive of uncles and aunts.

\section{Chandateristics of the Method}

The basic principle of the proposed method is that the risk score of a family member decreases from unity at age 30 as the farnily member grows older without developing the diseases, and if the family member develops a disease in question, the risk score for that menber is set at a centain level at that age. In this sense, this method should be called a "risk-subtracting" approsch, wheneas other conventional family risk evaluation methods are of a "jisk-adding" approach. In this risk-subtracting approach family members are treated as having $100 \%$ potential of developing the disease until age $\mathbf{3 0}$, followed by a gradual decrease with aging. In the conventional risk-adding approach family members without the disease are treated as non-burdened members regardless of their age until they develop the disease. The point is how to deal with a family member withou the diserse in question. In the conventional methods described in "Introduction", such a member is treated as having $0 \%$ risk at any age.

\section{Statistical Anatysis}

The degree of association was measured by the odds ratio, 
and the statistical test used was the chi-square test of independence ${ }^{\text {15. All the calculations were performed by the PCSAS }}{ }^{\text {". }}$.

\section{festurts}

The questionnaire was reaurned by 1,714 sudents (a retum rate of $71.6 \%$ ). Among these, 39 students missed cholesterol determination, so data for 1,675 sudents and 18,115 family members were available in the qualitative and semi-quantita tive methods. In 91 families an age variable serving as the "Risk age" was missing, so data for 1,584 students with 17,127 family members were available in the proposed method.

Among the 1,675 analyzed family histories $167(10.0 \%)$ were returned after the health examination. A possibility of recall bias was assessed by checking the proportion of students with positive family histories of angina pectoris or myocandial infarction, Among the bigh (above the 90 th percentile) atherogenic index students, the proportion was low in the late returnex group: 41.6\% for early rehirners and $36.8 \%$ for late returners. Furthermone, the student's atherogenic index was noc told, though the toial and HDL cholesternol levels were released. Therefion, it is unlikely that a reall bias produced positively distorted results.

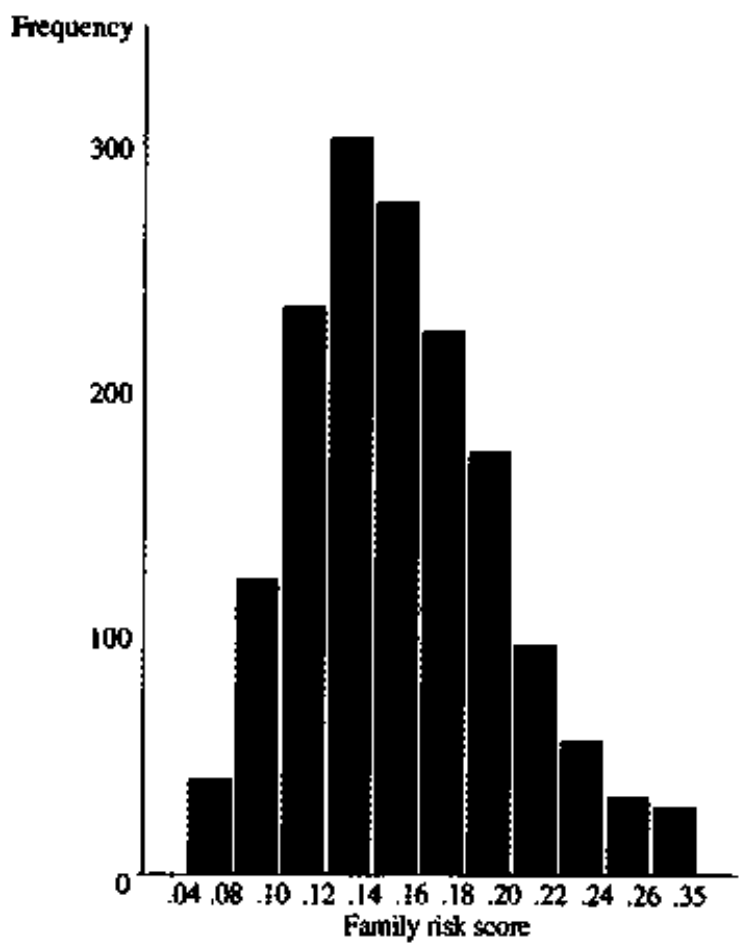

Floure 1. The distribution of the family risk score. The scale of the risk score ts 0.02 except for both ends. The figures on the scale indicate the kft end of the risk score category.
The 90th percentile of the high atherogenic index was 2.74 . The 90th percentile has been recommended as the dividing point to classify high risk childen and youth for adulthood cardiovascular disease 20 m.

The atherogenic index has not been widely used outside Japan. Rather, the ratio of kw density lipoprotein (LDL) cholesterol to HDL chotesterol has been frequently used. But both are highly correlated as can be easily undenstood from their definitions. In this study data the Peasson correlation coefficient between the index and the ratio was 0.97 among the students in the lattrer 2 years in whom triglyceride was measured and whene the LDL cholesterot was estimated by [Totol cholesterol - FDL cholesterol - 1/5 triglyceride] ${ }^{20}$.

The distribution of the fantily risk scone by the proposed method is shown in Figure 1 . The score ranged from 0.0456 to 0.3439 with a mean of 0.1516 . The quartile values were: 25 th percentile $=0.1199 ; 50$ th percentile (median) $=0.1469$; 75th percentile $=0.1785$. The distribution is slightly skewed to higher scores. Its normality was not accepted by the significance test using the UNIVARIATE procedure in the SAS software However, the logarithrn of the risk score did not depart from the nomal distribution ( $\mathrm{p}>0.05$ ).

Table 2 shows the results regarding sturdents' atherogenic

Table 2. Sudents' atherogenic index and fandly history risk by the propoced method among 1584 students.

\begin{tabular}{lcccccc}
\hline & & \multicolumn{5}{c}{ Family risk score by percentile } \\
& $0-25$ & $25-50$ & $50-75$ & $75-100$ & Total \\
\hline Students' & $<90$ percentile & 366 & 364 & 350 & 347 & 1427 \\
athero- & $(\%)$ & $(25.6)$ & $(25.5)$ & $(24.5)$ & $(24.3)$ & $(100)$ \\
genic & $>90$ percentile & 30 & 32 & 46 & 49 & 157 \\
index & $(\%)$ & $(19.1)$ & $(20.4)$ & $(29.3)$ & $(31.2)$ & $(100)$ \\
\hline
\end{tabular}

Table 3. Students' alherogenic index and fanily history rist by the grabitative method anche 1675 sucterss.

\begin{tabular}{lcccccc}
\hline & \multicolumn{5}{c}{ Family risk by point } \\
& 0 & 1 & 2 & $>=3$ & Tokal \\
\hline $\begin{array}{l}\text { Students } \\
\text { athero }\end{array}$ & $<0$ percentile & 1004 & 345 & 120 & 40 & 1509 \\
genic & $(\%)$ & $(66.5)$ & $(22.9)$ & $(8.0)$ & $(2.7)$ & $(100)$ \\
index & $(\%)$ percentile & 103 & 40 & 14 & 9 & 166 \\
& $(\%)$ & $(62.0)$ & $(24.1)$ & $(8.4)$ & $(5.4)$ & $(100)$ \\
\hline
\end{tabular}

Two points for the presence of a disease concerned in the past history of a parent, and 1 point for the presence in the past history of a grandpareat. 
index and the fannily risk of coronery heart tisease by the study method. Among the 157 "high atherogenic index" students, the proportion in the quartile family risk groups gradually rose, whereas among 1427 "nomal" students the proportion was nearly equal: around $25 \%$ in the 4 groups. The chi-square test of independence was significant ( $p<0.05$ ). When the farmily risk was divided into two, betow or above the 50th percentile [easily constructed from Table $1: 730(51.2 \%)$ and 697 (48.8\%) for the nomal students and $62(39.5 \%)$ and 95 (60.5\%) for the high atherogenic students], it showed a significant difference ( $\mathrm{p} \times 0.01)$, with an odds ratio of 1.60 (95\% confidenoe interval: $1.15-2.25$ ). When the lowest quartile group and the highest quartile group were compened, the odds ratio was 1.72 (95\% confidence interval: 1.07-2.78).

Table 3 shows the results of the qualitative method. Wherever the 4 groups were regrouped into two groups by risk point, there was no statistically significant difference (p>0.05). The odds ratio, when the risk groups were divided by point between 0 and 1 , was 1.22 (95\% confidence inverval : 0.871.69). Other divisions would be of less meaning in practical application, resulting in identifying a small proportion of high atherogenic spudents. In the analysis in which uncles and aumts were included, though data are not shown, the difference in the proportions between the high and normal anerogenic index gmoup was similar to the difference in Table 3.

Table 4 shows the results of the semi-quantitative method Wherever the 4 groups were regrouped into two, there was no statistically significant difference ( $p>0.05$ ). Since one point was given when a farily member developed a coronary heart disease below age 60, the proportion in the 0 point group was much higher than that in Table 3 . The odds ratio, when the risk goups were divided by point between 0 and 1 , became a little lerger than that of the qualitative method: 1.38 (95\% confidence interval: 0.92-2.07). However, the propurtion of students

Table 4. Snudents' wherogenic index and farmily history risk by the semi-quantitative methodamorig 1675 studerts.

\begin{tabular}{lcccccc}
\hline & \multicolumn{5}{c}{ Fumily risk by point } \\
& 0 & 1 & 2 & $>=3$ & Total \\
\hline Suxdents & $<0$ percentile & 1279 & 179 & 39 & 12 & 1509 \\
gthero- & $(8)$ & $(84.8)$ & $(11.9)$ & $(2.6)$ & $(0.8)$ & $(100)$ \\
genic & $>90$ percentile & 133 & 25 & 6 & 2 & 166 \\
index & $(\$)$ & $(80.1)$ & $(15.1)$ & $(3.6)$ & $(1.2)$ & $(100)$ \\
\hline
\end{tabular}

ane point for the presence of angina pectoris or myocardial infarction below age 60 in the past history of a parent, grandparent. uncle and aunt. identified as high risk became much smaller. The results when 2 points were given for a parental onset were very close to the results in Table 4 .

\section{Discussion}

The method we propose here yielded better results than the frequently used conventionsl methods in selecting high atherogenic index students, thereby in identifying candidates for coronary disease from family history. The semi-quantitative method, which controls for age of family members to some degree, yieliled a larger odds ratio than that of the qualitative method without any control for age of family members. The inefficiency, some claimed, in finding high cholesterol children from farnily history by the semi-quantiative method used in the U. S. A. "would be inproved to some extent by the use of this proposed method. However, sensitivity, specificity, and positive and negative predictive values may not be high enough to use this family risk as a single index for screening. Combination with other risk factors will be necessary if applied to screening. The above indices for screening when applied to ongoing sereening programs combined with other risk factors need to be detennined together with cux-off points which meet various purposes.

A possible argument against the proposed method exists: there is no essurance that the high ahenogenic index sudents will develop cononary heart disease after age 30 . Strictly speaking, full credit to this stuxly will be given after an analysis 40 or 50 years later when the students become old enough to have developed such diseases. As a long term research strategy, we selocted the school for that aim. But there exist backup and reinfoncement. Tracking of serum cholesterol, a risk factor for adulthood coronary disease, through adolescence and adulthood is not low particularly among those sbove the $80 \mathrm{hh}$ and and 90th percentile x. In addition. young men with high serum cholesterol lewets wene reported to have an increased risk of coronary heart disease in mid-life 27 to 42 years later 20 . The relative risk between the below 25th and over 75th percentile of serum cholesterol was 2.01 for coronary heart disease and 1.72 for cardiovascular diseases -incidentally very close to the resultes in this study.

Another question is misclassification in the family history. The questionnaire was filled in by parents. Therefore, they filled in the information on themselves and on their brothers, sisters and parents. It is unlikely that people in their $40 \mathrm{~s}$ and 50s were mistaken in answering present age and age at death of their siblings and parents. The grandparents in the questionnaire were mostly in their $60 \mathrm{~s}$ and 70 s by present age $\alpha$ age at death. Their sons and daughters-parents in the questionnaire-most likely know the past history of such serious diseases like angina pectoris and myocardial infarction among their parents and onset should be fairly reliable if 
expressed by decade age. We examined the precision, or reliz bility of the family history questionnaire used in this study ${ }^{20}$. The questionnaire was administered twice with a one-yen interval. The proportion of contradicting answers-namely inderchange between presence and absence of the past history. and discrepancy in age at onset-between the two surveys was low. In myocandial infarction it was below $1 \%$ arnong parents, uncles and aunts, and around $4 \%$ among granipanens. In angina pectoris it was below $2 \%$ among parents, uncles and aunts, and around $5 \%$ among grandparents. Inaccuracy, namely discrepancy between answers and true evidence, is diffictilt to confirm. There has been no epidemiological study, to our knowledge, which examined the accuracy of a questionnaire on the family history of coronary heart disease. From these results it can be said that misclassification in the past history would not have distorted the results so greatly as to endinger the conclusion of the present study.

Seemingly inconsistent results were projected in some studies. The inconsistency seems to derive from a different shudy design and a different study population. In a study in Utah, the

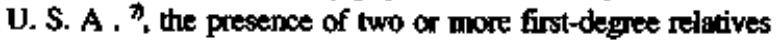
with coronary heart disease before age 50 in a family-the semi-quantitative method-showed a good discrimimatory ability with high relative risks against fanilies without such members. In the study, bowever, subsequent incidence among nonaffected family members, rather than high school students, was examined. In another report ", the results obtained in adults were extrapolated to a pediatric-age popularion. In these approaches the relative risk was unstable and small among young families ${ }^{n}$. Therefore, these methods seem to be inefficient when applied to a pectiatric-age population. The risk-subtracting approach of our method was devised to overcome this type of problem, especially in evaluating young families where most parents are in their 40s and earty 50s. There remains a possibility that the inconsistency may be due to differences in the scudy population: a U. S. population with a much higher mortality of comonary heart disease than a Japanese population 2. In this case, this proposed method will yield a higher odds ratio than the odds ratio projected in this study and the method should be quite useful.

The formula for the risk calculation is generalized as (A / Risk age $)^{n}$. The rational for this formula is based on observations thar age-specific incidence in cardiovascular diseases and the proportion of a positive history in this study ane approximated by a(age)", where a is a constant. To obtain the score which varies from 0 to 1 , its inverse was taken. In this study the term $\mathrm{A}$ in the formula was 30 , which meant the carliest age of onset of the diserses concemed. The power $n$ of 4 was used to make the power in the model closest to the age-specific proportion of a positive history of the disease obtained from the study data. Different powers will be employed responding to different age-specific proportions in different diseases. With the sudy data, however, when $n$ was changed from 3 to 7, the results were very similar to those shown in Table 2.

The method can be modified Some weight may be given to death from the disease. In this risk-subtracting approach a family member who is alive withoux the disease at age 40 and a member who died of the disease at age $\mathbf{4 0}$ give the same risk score. This sounds inappropriate, but when 5 years were subtracted from age at dench and age at onset, the results did not depart much from those of Table 2. This was not a serious one. Some ways of dealing with young age at death, say by censoring mechodk, may rechuce the proportion of families falsely ranked in high risk groups due to premature deaths. One of the possible methods is a life-table approach, but this also shanes some of the drawbecks described in the introduction. Use of age-specific proportion of a positive history by sex instead of the n'th power of the risk ase may result in more accurate risk assessment. But these measures require a consensus on the weights, more complex calculations or detailed data from outside sounces. Simplicity, we think, surpasses a little increase in efficiency by modification, if a method is to be used willely.

The risk-subtracting approach, a new concept in genetic epidemiology, has a practical advantage if used in a prevention program. Since the life-style established during childhood seems to facilitate atherosclerosis through adolescence and adulthood ", the preventive program needs to start at childhood when identifying those at high risk is not an easy task. Therefore, the program, mostly educational, may better be directed to al children and youth maker than to high risk individuals who are not easily identified. As family members grow older and children reach adolescence, those ax high risk or low risk become apparent gradually from family histary and from other screening methods. Those found to be at high nisk can be requested more strongly to adopt a healthy life-style established through health education with necessary medical intervention. Those at low risk may maimtain their life-style, and when the decrease of risk slows down because some family members develop such diseases, necessary intervention can be taken. The risk-subtracting nanure of the proposed method is most appropriate for this approach. In this sense the method is of a "preventive" nature, whereas the conventional risk-adding methods are of a "cumative" nature.

Since the proposed method is fully quantitative ranging from near 0 to I following a near-bormal distribution-made normal by logarithm transformation-, and no anea- or country-specific data, such as age-specific incidence or prevalence, are required, it can be used anywhere as a standend method for vartious purposes. The calculated score for a family serves as a risk indicator of that family. The mean and the standand deviation of a population serve as population risk indicators. Their comparisons among different ethnic and culuinal populations or at different times will be useful in analyzing genetic and environ- 
mental interactions affecting various diseases. A cut-off point for bigh risk groups is set at various levels in the family risk soure to meet various purposes.

Obtaining required data including age at onset by decade does not present much difficulty. The validity and usefulness of our method may well be verified in other commtries and in cther diseases where appropriate data are available.

\section{ACKNOWLECDMENTS}

Part of the study was presented at the scientific meetings of the International Epidemiological Association and of the Japan Epidemiological Association. Supported by a grant-in-aid "Prevention of adult vascular diseases from childhood" from the Ministry of Health and Welfare, Japan. We thank Dr. T. Sekihara for his help in data collection, Ms. S. Fujinaka for data management, and Dr. S. Watanabe for his valuable advice.

\section{References}

1. A WHO Expert Committee. Prevention in childhood and youth of adult cardiovascular diseases: time for action. Technical Repon Series, No.792, 1990 ; World Health Organization, Geneva

2. Motulsky AG. Genetic research in coronary heart disease. In; Roo DC, Elston RC, Kuller LH, Feinleib M, Carter C, Havlik $R$, eds. Genetic epidemiology of cononary heart disease. Alan R Liss, Inc., New York. 1984 : 541 -548.

3. Goldbourt U, Neufeld H/N. Genetic aspects of arteriosclerosis. Arteriosclerosis 1986: 6: 357-377.

4. NCEP Expert Panel on Blood Cholesterol Levels in Children and Adolescents. National Cholesterol Education Program (NCEP): Highlights of the repont of the expert panel on blood choksterol levels in children and adolescents. Pediatrics 1992 ; 89 : 495-501.

5. Shear CL, Butke GL, Freedman DS, Berenson GS. Value of childhood blood pressure measurements and family history in predicting funure blood pressure stzilus : results from 8 years of follow-up in the Bogalusa Heart Sudy. Pediatrics 1986 : 77 : 862-869.

6. Nora JJ. Identifying the child at risk for coronary disease as an adult: a strategy for prevention. J Pediatr 1980; 97 : 706-714.

7. Hunt SC. Williams RR. Barlow GK. A comperison of positive family history definitions for defining risk of future disease. J Chron Dis 1986 ; 39 : 809-821.

8. Sajto T, Purukawa T, Nanri S, Saito I, Nagano S. lmportance of age factor in assessing family history of comorary heart disease. J Epidemiol 1995 ; 5: 109-112

9. Marenberg ME, Risch N, Berkman LF. Floderus B, de Faire U. Genetic susceptibjility to death from coronary heart disease in a study of twins. N Engl J Med 1994 ; $330: 1041-1046$.

10. Berenson GS (editorial). Cholesterol-myth ws, reality in pediarric practice. Am J Dis Child 1993 ; 147 ; 37 L-373.

11. Allain C C, Poon L S, Can C S. Richmond W, Fu P C. Enzymatic determination of total serum cholesterol. Clin Chem $1974 ; 20 ; 470-475$.

12. Yajima $\mathbf{H}$, Ueki $\mathbf{H}$. Determination of HDL-cholesterol and its significance in clinical practice. Medicine and Drug Journal 1980: $16: 41-49$ (in Japanese).

13. Goto Y. Atheroscierosis-a recent view. The Journal of Therapy $1979 ; 61 ; 813-819$ (in Japanese).

14. Yano $Y$, Irie $N$, Homma $Y$ et al. High density lipoprotein cholesterol level in Japanese. Japanese Journal of Geriatrics $1979 ; 16: 421-430$ (in Japanese).

15. Hosali J. Prevention of atherosclemosis from childhoodassaciation between atherogenic factors and serum total and HDL cholesterol. Pediatries of Japan $1980 ; 21: 179$ 184 (in Japanese).

16. Ohji $T$, Takghashi $\mathrm{K}$, Chiba $\mathrm{K}$ el al Lipoprotein cholesterol and atherogenic index in healthy children of 5 years old. Journal of Child Health $1992 ; 51 ; 600-604$ (in Japanese).

17. Stem C. Principles of Human Genetics. 3nd edition, W H Freeman and Company, San Francisco, 1973 : 137-143.

18. Woolson RF. Statistical methods for the analysis of biomedical dara. John Wiley \& Sons, New York, 1987 ; 246260.

19. SAS Institule Inc. PC-SAS, SAS/BASE, SAS/STAT software. Version 6, Cary, NC, USA.

20. Burke GL, Cresanta J,, Shear CL. Miner MH, Berenson GS. Cardiovascular rist factors and their modification in children. Cardiol Clin 1986 ; 4 : $33-46$.

21. Shear CL, Burke GL, Freedman DS, Webber LS, Berenson GS. Designation of children with high blood pressure-considerations on percentile cut points and subsequent high blood pressure: the Bogalusa Heart Study. Am J Epidemiol $1987: 125: 73-84$.

22. Laue RM. Lee J, Clake WR. Factors affecting the relationship between childood and adult cholesterol levels: the Muscatine Study. Pediatrics 1988 ; 82 ; 309-318.

23. Gidding SS. The rationale for lowering serum cholestero' levels in American children. Am J Dis Child $1993 ; 147$ : 386-392.

24. Friedewald W T, Levy R I, Frectrickson D S. Estimation of the concentration of low-density lipoprotein cholesterol in plasma, without use of the preparative ultracentrifuge. Clin Chem $1972 ; 18: 499-502$.

25. Porkka KVK, Vijkari JSA, Taimela S, Dahl M, Åkerblom HK. Tracking and predictiveness of serum lipid and lipoprotein measurements in chikbood: a 12 year follow-up. Am J Epidemiol 1994 : 140 : 1096-1110. 
26. Klag MJ, Ford DE, Mead LA, He J, Whelioe PK, Liang KY, Levine DM. Senum cholesterol in young men and subsequent cardiovascular disease. N Engl J Med 1993 ; 328 : 313-318.

27. Saito T, Narri S, Saito I. Reliability of a questionnaire survey on the farnily history of atherosclerotic dieeses.
Abstracts of the 55th scientific meeting of the Japan Society of Public Health . Jpn J Public Health 1996 ; 43 : 450 (in Japanese).

28. Uemura $K$, Piss Z. Theods in candiovascular disease mortality in industrialized countries since 1950. Word He:lh Statistics Quarterly 1988 ; 41 : 155-178. 